\title{
Isoastragaloside I inhibits NF- $\kappa B$ activation and inflammatory responses in BV-2 microglial cells stimulated with lipopolysaccharide
}

\author{
HONGSHUAI LIU, FEI HUANG, HUI WU, BEIBEI ZHANG, HAILIAN SHI, XIAOJUN WU and ZHIBI HU \\ Shanghai Key Laboratory of Compound Chinese Medicines, The Ministry of Education (MOE) Key Laboratory for \\ Standardization of Chinese Medicines, Institute of Chinese Materia Medica, Shanghai University of \\ Traditional Chinese Medicine, Shanghai 201203, P.R. China
}

Received June 6, 2016; Accepted August 25, 2017

DOI: 10.3892/ijmm.2017.3114

\begin{abstract}
The excessive activation of microglia in many neurodegenerative diseases is detrimental to neuronal survival. Isoastragaloside I (ISO I) is a natural saponin molecule found within the roots of Astragalus membranaceus, a famous traditional Chinese medicine. In the present study, the anti-inflammatory effects and the mechanisms of action of ISO I on activated BV-2 cells stimulated with lipopolysaccharide (LPS) were investigated. ISO I dose-dependently inhibited the excessive release of nitric oxide (NO) and tumor necrosis factor (TNF)- $\alpha$ in the LPS-stimulated BV-2 cells. Moreover, it decreased the production of inducible NO synthase (iNOS) and cyclooxygenase-2 (COX-2), and mitigated the gene expression of interleukin (IL)-1 $\beta$, TNF- $\alpha$ and iNOS induced by LPS. Further experiments revealed that ISO I decreased the phosphorylation levels of nuclear factor- $\kappa \mathrm{B}(\mathrm{NF}-\kappa \mathrm{B})$, and suppressed its nuclear translocation and transactivation activity. In addition, it inhibited the activation of signaling pathway molecules, such as PI3K, Akt and mitogen-activated protein kinases (MAPKs). Taken together, our findings suggest that ISO I prevents LPS-induced microglial activation probably by inhibiting the activation of the $\mathrm{NF}-\kappa \mathrm{B}$ via PI3K/Akt and MAPK signaling pathways, indicating its therapeutic potential for neurological diseases relevant to neuroinflammation.
\end{abstract}

Correspondence to: Dr Hailian Shi or Dr Xiaojun Wu, Shanghai Key Laboratory of Compound Chinese Medicines, The Ministry of Education Key Laboratory for Standardization of Chinese Medicines, Institute of Chinese Materia Medica, Shanghai University of Traditional Chinese Medicine, 1200 Cailun Road, Shanghai 201203, P.R. China

E-mail: shihailian2003@163.com

E-mail: xiaojunwu320@126.com

Key words: isoastragaloside I, microglia, nuclear factor- $\kappa \mathrm{B}$, neuroinflammation, mitogen-activated protein kinases

\section{Introduction}

As resident innate immune cells in the central nervous system (CNS), similar to peripheral macrophages, microglial cells help to enhance host defence by eliminating pathogen attack (1). However, the sustained and uncontrolled activation of microglia leads to the accumulation of excessive detrimental substances, most notably nitric oxide (NO), free radicals and pro-inflammatory cytokines [e.g., interleukin (IL)-1 $\beta$ and tumor necrosis factor- $\alpha(\mathrm{TNF}-\alpha)]$ that may finally lead to neuronal destruction (2). Indeed, microglial activation is one of the main pathological characteristics in the processes of many neurological diseases associated with neuroinflammation, such as Alzheimer's disease, Parkinson's disease and multiple sclerosis. The suppression of the activated microglia has been suggested to benefit the prevention of these neurodegenerative disorders $(3,4)$.

$\mathrm{NF}-\kappa \mathrm{B}$, one of the Rel family transcription factors, is a primary regulator of genes of many pro-inflammatory cytokines or mediators, such as TNF- $\alpha$, IL-1 $\beta$ and inducible NO synthase (iNOS), as well as cyclooxygenase-2 (COX-2) $(5,6)$. Once activated by phosphorylation, NF- $\kappa \mathrm{B}$ is translocated to the nucleus, and transactivates downstream gene expression. Inhibitors of NF- $\mathrm{NB}$ have been suggested in the treatment of many inflammatory diseases (7). Lipopolysaccharide (LPS), a prototypical endotoxin, is able to stimulate the inflammatory responses in microglia by activating the $\mathrm{NF}-\kappa \mathrm{B}$ signaling pathway $(8,9)$. The LPS-induced activation of BV-2 microglial cells has been used widely for the studies of anti-microglial activation drugs (10-12).

Astragalosides are the main active saponins of Astragalus membranaceus (A. membranaceus), a well-known traditional Chinese medicine with antioxidative, immunoregulatory, anti-inflammatory and neuroprotective properties $(13,14)$, that have been demonstrated to benefit both the peripheral nervous system and CNS (15-17). Isoastragaloside I (ISO I) is one of the saponin molecules found within A. membranaceus (18), which has been demonstrated to alleviate insulin resistance and glucose intolerance in obese mice (19). However, little is known about whether it can inhibit microglial activation and whether it is beneficial in neurological diseases. In this 
study, the inhibitory effects of ISO I on inflammatory mediator production in BV-2 microglial cells stimulated with LPS were explored. Moreover, the possible underlying molecular mechanisms were investigated. Our findings indicated that ISO I may be an effective candidate for use in the treatment of various neurodegenerative disorders characterized with microglial activation.

\section{Materials and methods}

Drugs and reagents. ISO I (HPLC purity $\geq 98 \%$ ) was purchased from Shanghai Lightgoal Industry Co., Ltd. (Shanghai,

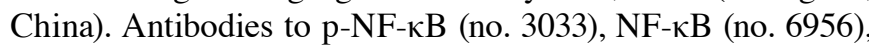
p-IкB (no. 2859S), IкB (no. 4812S), Akt (no. 2920), p-phosphoinositide 3-kinase (PI3K; no. 4228), p-p38 mitogen-activated protein kinase (MAPK; no. 9215), p38 MAPK (no. 9212), p-JNK (no. 9255), JNK (no. 9252), p-extracellular signal-regulated kinase (ERK)1/2 (no. 4377), ERK1/2 (no. 4348) and glyceraldehyde 3-phosphate dehydrogenase (GAPDH; no. 5174) were all obtained from Cell Signaling Technology Inc. (Danvers, MA, USA). Lamin B1 (no. 6581-1) and PI3K antibodies (no. 3838-1) were both obtained from Abcam (Cambridge, UK). The TNF- $\alpha$ ELISA kit was from eBioscience, Inc. (San Diego, CA, USA).

$B V-2$ cell culture and treatment. BV-2 microglial cells were supplied by the American Type Culture Collection (ATCC; Manassas, VA, USA) and were cultured in Dulbecco's modified Eagle's medium (DMEM) supplemented with $10 \%$ fetal bovine serum (FBS), $100 \mathrm{U} / \mathrm{ml}$ penicillin and $0.1 \mathrm{mg} / \mathrm{ml}$ streptomycin. The cells were seeded in 6-, 12- or 96-well plates at a density of $2 \times 10^{5}$ cells $/ \mathrm{ml}$ according to the requirement of the different experiments.

For the examination of iNOS and COX-2, and mRNA expression pattern assay, the cells were pre-treated with ISO I $(100 \mu \mathrm{M})$ or dexamethasone (Dex; $10 \mu \mathrm{M})$. Two hours later, they were incubated with LPS (200 $\mathrm{ng} / \mathrm{ml})$ for $20 \mathrm{~h}$, and were harvested for further western blot analysis and quantitative PCR (qPCR) assay.

For the analysis of activated PI3K and Akt, the cells were pre-treated with ISO I $(100 \mu \mathrm{M})$ for $2 \mathrm{~h}$ followed by LPS (200 ng/ml) stimulation for 5, 15 and $30 \mathrm{~min}$, respectively. The cells were then lysed in CelLytic ${ }^{\mathrm{TM}}$ MT mammalian tissue lysis reagent with phosphatase and protease inhibitor cocktail (all from Sigma-Aldrich, St. Louis, MO, USA) on ice for $0.5 \mathrm{~h}$. Following centrifugation at $12,000 \mathrm{rpm}$ for $15 \mathrm{~min}$ at $4^{\circ} \mathrm{C}$, the supernatant of the lysate was subjected to western blot analysis.

For the nuclear translocation assay of $\mathrm{p}-\mathrm{NF}-\kappa \mathrm{B}$, nuclear extract of the cells was collected using a respective kit (NE-PER ${ }^{\circledR}$ Nuclear and Cytoplasmic Extraction Reagents; Thermo Fisher Scientific, Inc., Rockford, IL, USA), and further used for western blot analysis.

Cytotoxicity and pro-inflammatory factor assay. To examine the effects of ISO I on cell viability, the BV-2 cells were treated with ISO I $(0,25,50$ and $100 \mu \mathrm{M})$ for $24 \mathrm{~h}$, the cell viability of which was assessed using the Cell Counting Kit-8 (CCK-8) (Dojindo Laboratories, Kumamoto, Japan). For the subsequent experiments, following pre-treatment with ISO I $(0,25,50$ and $100 \mu \mathrm{M})$ or Dex $(10 \mu \mathrm{M})$ for $2 \mathrm{~h}, \mathrm{BV}-2$ cells were stimulated with LPS (200 ng/ml) for $20 \mathrm{~h}$, and the culture medium was collected and subjected to further analysis.

The release of NO in the medium was evaluated by Griess assay as previously described (20). In brief, following incubation with nitrate reductase for $1 \mathrm{~h}$ at $37^{\circ} \mathrm{C}$, the medium was mixed with an equal volume of Griess reagent (SigmaAldrich). The optical density of the mixture was measured immediately at $540 \mathrm{~nm}$. The concentration of nitrate in the medium was calculated by a standard curve of sodium nitrite. The concentration of TNF- $\alpha$ was determined using a TNF- $\alpha$ ELISA kit according to the manufacturer's instructions.

Western blot analysis. Proteins were extracted from the cells by sonication in CelLytic ${ }^{\mathrm{TM}}$ MT mammalian tissue lysis reagent with protease and phosphatase inhibitor cocktails. Following centrifugation at $12,000 \mathrm{x}$ for $15 \mathrm{~min}$ at $4^{\circ} \mathrm{C}$, the supernatant of the lysate was collected. Proteins in the supernatant were separated by $10 \%$ SDS-PAGE and transferred onto PVDF membranes. After blocking in 5\% skim milk for $0.5 \mathrm{~h}$, the membranes were incubated with respective antibodies against p-NF- $\mathrm{B}(1: 1,000), \mathrm{NF}-\kappa \mathrm{B}(1: 1,000)$, iNOS $(1: 1,000), \mathrm{COX}-2$ $(1: 1,000), \mathrm{p}-\mathrm{I} \kappa \mathrm{B}(1: 1,000), \mathrm{I} \kappa \mathrm{B}$, Lamin B1 $(1: 1,000)$, Akt $(1: 1,000)$, p-Akt $(1: 1,000)$, p-PI3K $(1: 1,000)$, PI3K $(1: 1,000)$, p-ERK1/2 (1:1,000), ERK1/2 (1:1,000), p-JNK (1:1,000), JNK $(1: 1,000)$, p-p38 MAPK $(1: 1,000)$, p38 MAPK $(1: 1,000)$ and GAPDH $(1: 2,000)$ overnight at $4^{\circ} \mathrm{C}$. Thereafter, the membranes were incubated with secondary antibodies conjugated to horseradish peroxidase $(1: 5,000)$. The blots were developed using the ECL prime kit (GE Healthcare, Little Chalfont, UK). Protein bands were quantified using ImageJ $1.46 \mathrm{r}$ (National Institutes of Health, Bethesda, MD, USA).

$q P C R$. Total RNA was extracted using TRIzol reagent (Life Technologies, Carlsbad, CA, USA) and were reverse transcribed into cDNA using PrimeScript RT reagent (Takara Biotechnology Co., Ltd., Dalian, China). qPCR was performed using the TaqMan SYBR-Green qPCR kit (Life Technologies). The quantity of target genes was normalized to that of GAPDH in the same sample. The primer sequences were listed as follows: iNOS forward, 5'-AACATCAGGTCGGCCATCAC-3' and reverse, 5'-CCAGAGCCTGAAGTCATGTTTG-3'; TNF- $\alpha$ forward, 5'-AACCTCCTCTCTGCCGTCAAG-3' and reverse, 5'-CCTCCCAGGTATATGGGCTCAT-3'; IL-1 $\beta$ forward, 5'-TGGGCCTCAAAGGAAAGAATC-3' and reverse, 5'-GGT ATTGCTTGGGATCCACACT-3'; GAPDH forward, 5'-ATG TGTCCGTCGTGGATCTGA-3' and reverse, 5'-ATGCCTGC TTCAC CACCTTCT-3'.

Luciferase activity assay. The BV-2 cells were seeded in a 24-well plate at a density of $2 \times 10^{5}$ cells/well and cultured overnight. The cells were then transiently transfected with $\mathrm{NF}-\kappa \mathrm{B}$ reporter vector pGL6 (luc2P/NF- $\kappa \mathrm{B}-\mathrm{RE} / \mathrm{Hygro}$ ) (Beyotime Institute of Biotechnology, Shanghai, China) and Renilla luciferase plasmid with Lipofectamine ${ }^{\mathrm{TM}}$ LTX and Plus reagent (Life Technologies). Twelve hours later, the cells were treated with ISO I $(100 \mu \mathrm{M})$ for $2 \mathrm{~h}$ followed by stimulation with LPS $(200 \mathrm{ng} / \mathrm{ml})$ for $20 \mathrm{~h}$. Afterwards, the cells were harvested and subjected to luciferase activity assay according to the manufacturer's instructions (Promega, Madison, WI, USA). The final NF- $\kappa \mathrm{B}$ activity was presented 

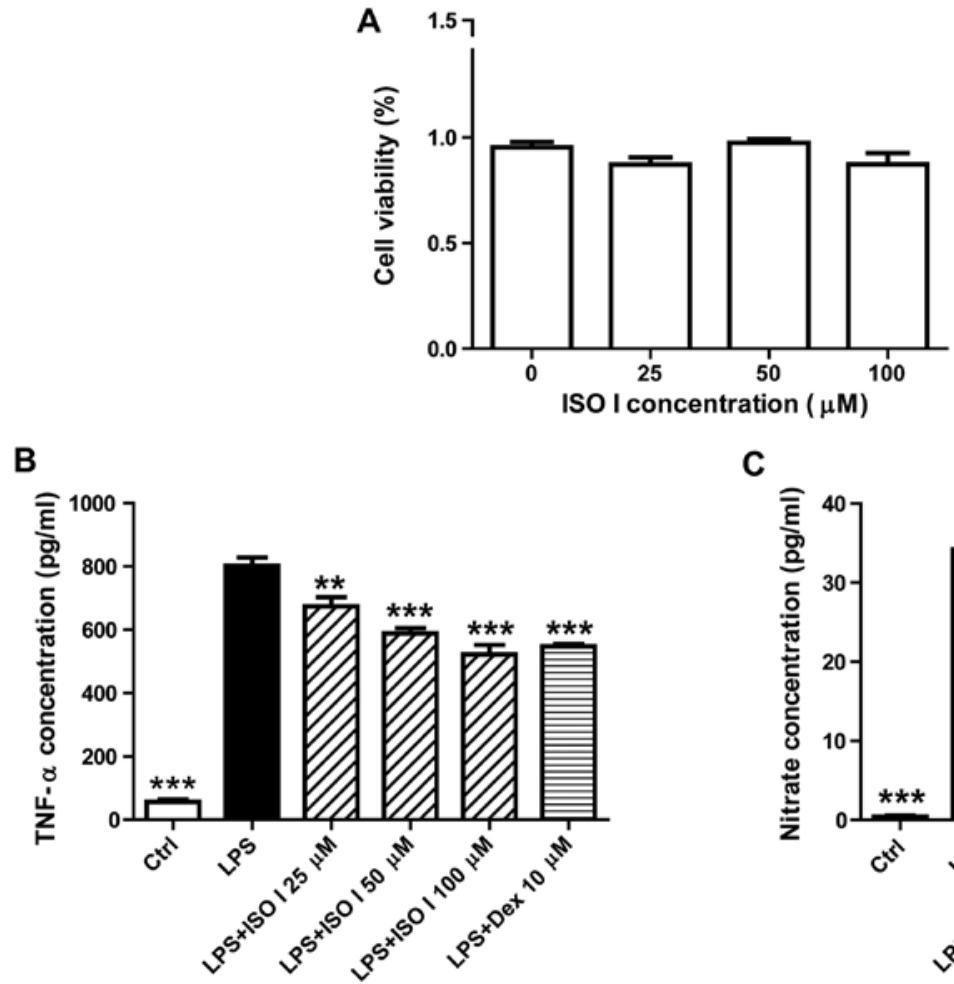

C

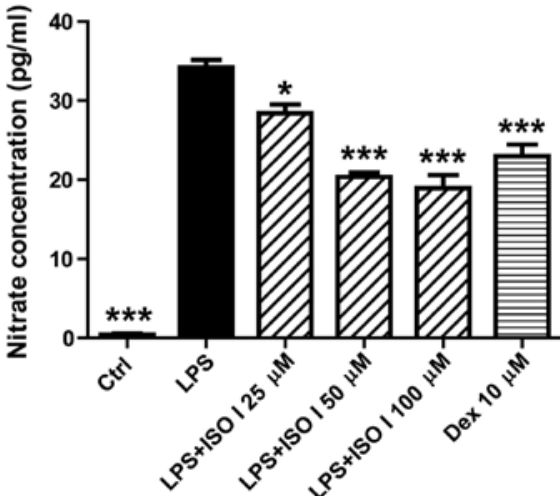

Figure 1. ISO I inhibits the release of inflammatory mediators from BV-2 cells upon lipopolysaccharide (LPS) stimulation. (A) Effect of ISO I on cell viability. (B) Effect of ISO I on tumor necrosis factor (TNF)- $\alpha$ secretion. (C) Effect of ISO I on nitric oxide (NO) release. " $p<0.05 ;{ }^{* *} p<0.01 ;{ }^{* * *}$ p $<0.001$ vs. LPS group, $\mathrm{n}=4$ /group, mean $\pm \mathrm{SEM}$. The data shown are one of the representative results from at least 3 independent experiments.

as the ratio of the activity of firefly luciferase to that of Renilla luciferase.

Immunocytochemistry (ICC). The BV-2 cells were seeded in 8 chamber slides (BD Biosciences, San Diego, CA, USA) at a density of $2 \times 10^{5}$ cells $/ \mathrm{ml}$. Tweety-four hours later, the cells were treated with or without ISO I $(100 \mu \mathrm{M})$ for $2 \mathrm{~h}$ followed by stimulation with LPS (200 $\mathrm{ng} / \mathrm{ml})$ for $20 \mathrm{~h}$. Thereafter, they were washed with phosphate-buffered saline (PBS), fixed with 4\% PFA, permeabilized and blocked in PBS with 5\% normal donkey serum and $0.1 \%$ Triton X-100. Half an hour later, cells were incubated with p-NF- $\mathrm{B}$ p65 antibody overnight at $4{ }^{\circ} \mathrm{C}$ After washing in PBS, they were further incubated with Alexa-594 conjugated secondary antibody at room temperature for $1 \mathrm{~h}$. At last, cells were sealed in medium with DAPI. Fluorescence images of the cells were acquired using an Olympus DX81 fluorescent microscope (Olympus, Tokyo, Japan).

Statistical analysis. All data are presented as the means \pm SEM. Differences among 3 or more groups were analyzed by one-way analysis of variance (ANOVA) followed by Dunnett's multiple comparison test using GraphPad Prism 5 software (GraphPad Software, Inc., La Jolla, CA, USA). Moreover, an unpaired Student's t-test was used to compare the differences between 2 groups. Differences were considered statistically significant at a value of $\mathrm{P}<0.05$.

\section{Results}

ISO I suppresses the production of pro-inflammatory mediators induced by LPS. Prior to the assessment of the anti-inflammatory effects of ISO I, the cytotoxic effects of ISO I on BV-2 cells were first examined by CCK-8 assay. As shown in Fig. 1A, treatment with ISO I at 25, 50 and $100 \mu \mathrm{M}$ did not affect the viability of the BV-2 cells. We then examined the effects of ISO I on LPS-stimulated BV-2 cells. As shown in Fig. 1B and C, LPS significantly induced the release of pro-inflammatory factors, such as TNF- $\alpha$ and NO $(\mathrm{P}<0.001)$. Moreover, it also increased the protein expression of iNOS and COX-2 (Fig. 2; $\mathrm{P}<0.001$ ). Following treatment with ISO I $(25,50$ or $100 \mu \mathrm{M})$, the production of all the pro-inflammatory factors was decreased $(\mathrm{P}<0.05$, $\mathrm{P}<0.01$ or $\mathrm{P}<0.001)$. Similarly, Dex, the positive control drug, also suppressed the production of all of the pro-inflammatory factors in the BV-2 cells when used at $10 \mu \mathrm{M}(\mathrm{P}<0.01$ or $\mathrm{P}<0.001)$. These results indicated that ISO I attenuated the inflammatory response in microglia upon LPS stimulation. Since ISO I at $100 \mu \mathrm{M}$ exhibited the optimal inhibitory effect, this concentration was selected for use in the subsequent experiments.

ISO I downregulates the mRNA expression of pro-inflammatory mediators induced by LPS. To determine the effects of ISO I on the mRNA expression of pro-inflammatory mediators in BV-2 cells upon LPS stimulation, qPCR analysis was performed. As shown in Fig. 3, the mRNA levels of TNF- $\alpha$, IL-1 $\beta$ and iNOS were markedly upregulated by LPS $(\mathrm{P}<0.001)$. However, treatment with ISO I $(100 \mu \mathrm{M})$ significantly inhibited the overproduction of TNF- $\alpha$, IL- $1 \beta$ and iNOS mRNA $(\mathrm{P}<0.01$ or $\mathrm{P}<0.001$ ), which was consistent with its effects on the protein levels of these pro-inflammatory mediators.

ISO I prevents the activation of $N F-\kappa B$ induced by LPS. To explore the role of ISO I on NF- $\kappa \mathrm{B}$ activation, a luciferase 


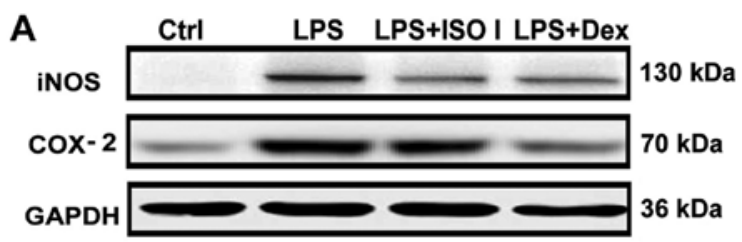

B

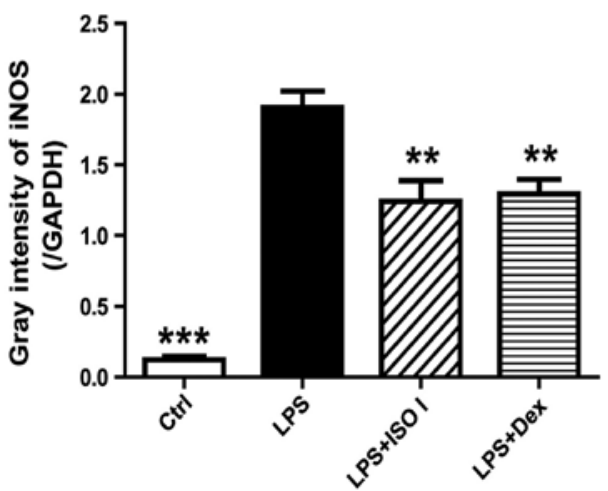

C

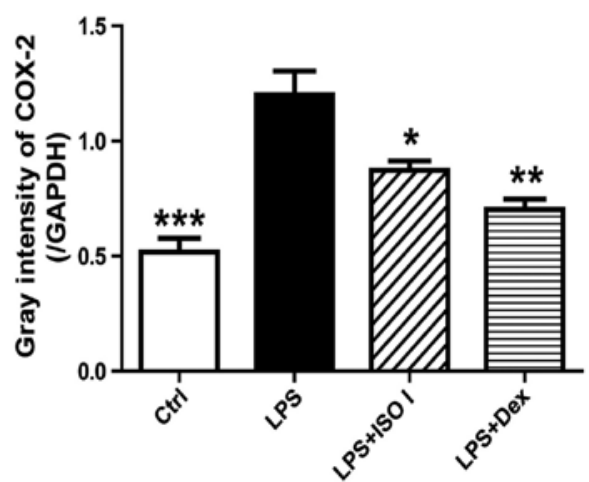

Figure 2. ISO I prevents the expression of inducible nitric oxide synthase (iNOS) and cyclooxygenase-2 (COX-2) in lipopolysaccharide (LPS)-stimulated BV-2 cells. BV-2 cells were pre-treated with ISO I $2 \mathrm{~h}$ prior to incubation with LPS $(0.2 \mu \mathrm{g} / \mathrm{ml})$ for $20 \mathrm{~h}$. (A) Western blot analysis. (B) Gray intensity analysis of iNOS. (C) Gray intensity analysis of COX-2. ${ }^{*} \mathrm{p}<0.05 ;{ }^{* *} \mathrm{p}<0.01 ;{ }^{* * *} \mathrm{p}<0.001$ vs. LPS group, $\mathrm{n}=3 /$ group, mean \pm SEM. The data shown are one of the representative results from at least 3 independent experiments.

A

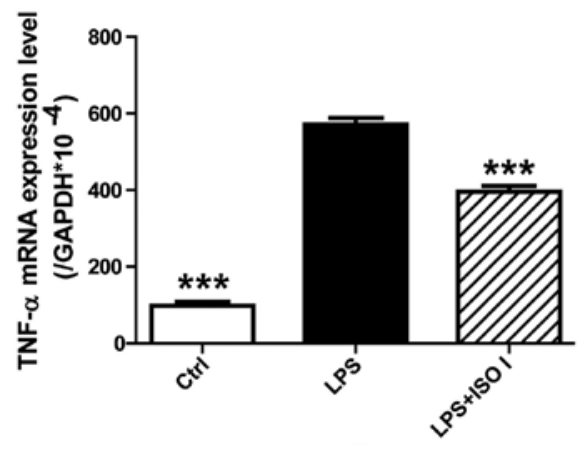

B

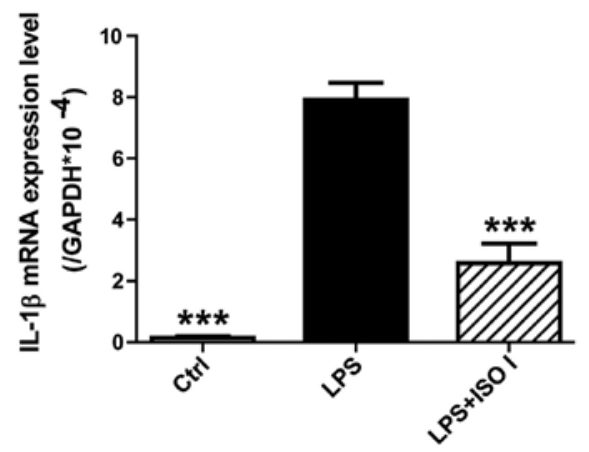

C

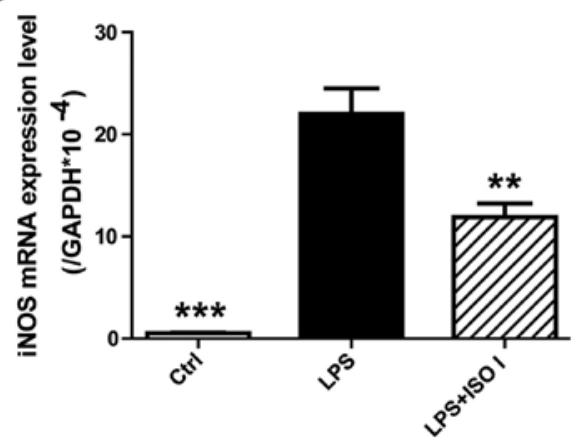

Figure 3. ISO I suppresses the mRNA expression of tumor necrosis factor (TNF)- $\alpha$, interleukin (IL)-1 $\beta$ and inducible nitric oxide synthase (iNOS) in lipopolysaccharide (LPS)-induced BV-2 cells. Cells were pre-treated with ISO I for $2 \mathrm{~h}$ prior to LPS stimulation $(0.2 \mu \mathrm{g} / \mathrm{ml})$ and total RNA was isolated $20 \mathrm{~h}$ after LPS stimulation. (A) Effect of ISO I on mRNA expression of TNF- $\alpha$. (B) Effect of ISO I on mRNA expression of IL-1 $\beta$. (C) Effect of ISO I on mRNA expression of iNOS. ${ }^{* *} \mathrm{p}<0.01 ;{ }^{* * *} \mathrm{p}<0.001$ vs. LPS group, $\mathrm{n}=4$ /group, mean \pm SEM. The data shown are one of the representative results from at least 3 independent experiments.

reporter assay was carried out. As shown in Fig. 4A, LPS stimulation led to a marked increase in NF- $\kappa \mathrm{B}$-luciferase activity $(\mathrm{P}<0.001)$ in the $\mathrm{BV}-2$ cells, which was reversed by ISO I $(\mathrm{P}<0.01)$. Moreover, as revealed by western blot analysis (Fig. 4B and C), ISO I treatment suppressed the increased phosphorylation of NF- $\mathrm{KB}$ induced by LPS $(\mathrm{P}<0.05)$. Accordingly, the elevation of phosphorylated I $\kappa$ B was lessened $(\mathrm{P}<0.05)$. 

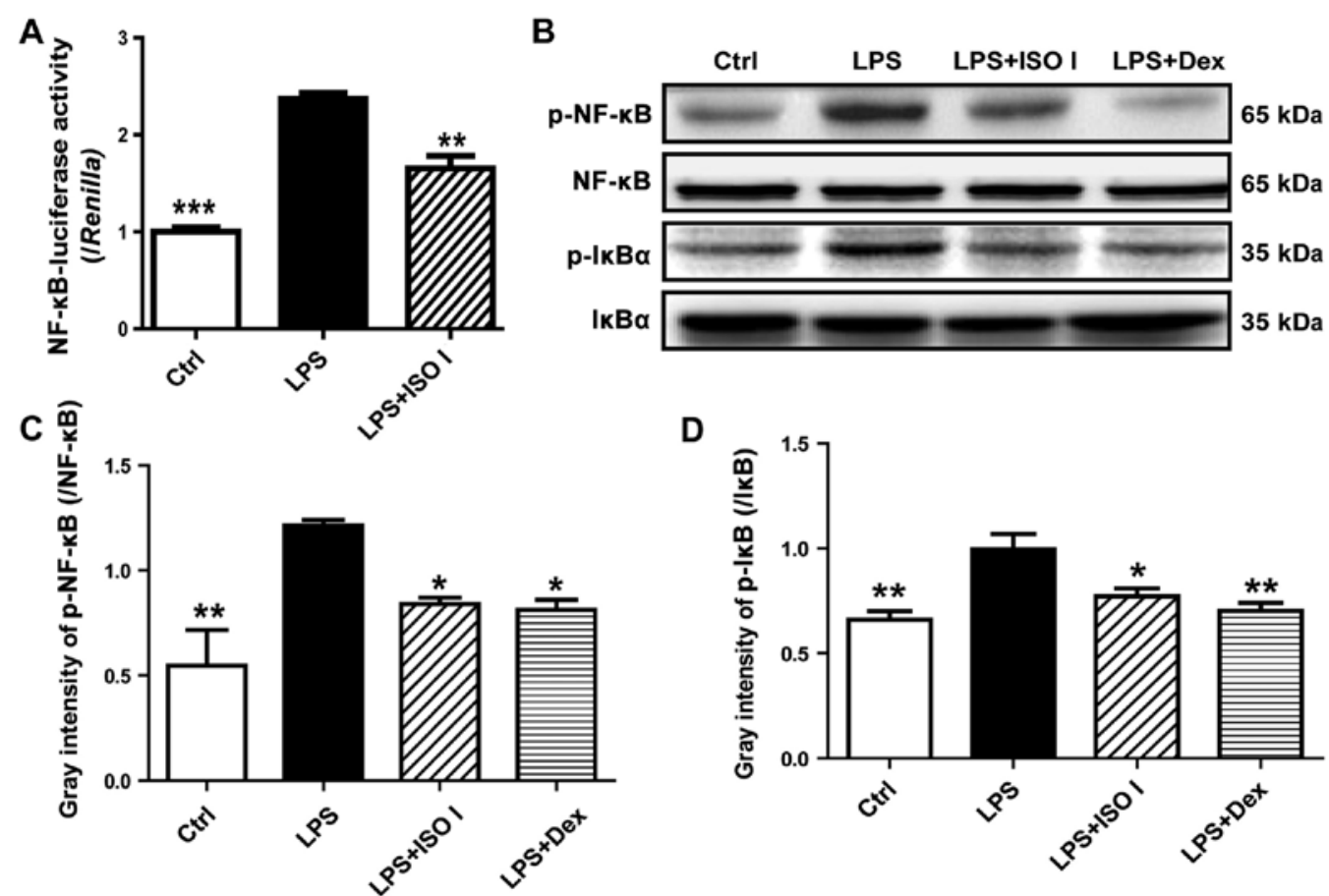

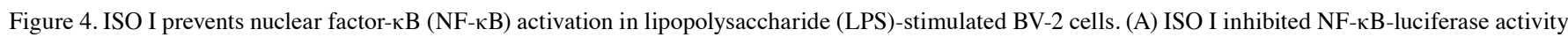
after LPS stimulation. ${ }^{* *} \mathrm{p}<0.01 ;{ }^{* * *} \mathrm{p}<0.001$ vs. LPS group, $\mathrm{n}=4$ /group, mean \pm SEM. (B) Western blot analysis. (C) Gray intensity of phosphorylated NF- $\kappa \mathrm{B}$. (D) Gray intensity of phosphorylated IкB. ${ }^{*} p<0.05 ;{ }^{* *} p<0.01$ vs. LPS group, $n=3$ /group, mean \pm SEM. The data shown are one of the representative results from at least 3 independent experiments.

To further confirm the inhibitory effects of ISO I on the activation of NF- $\mathrm{KB}$, the nuclear translocation of phosphorylated NF- $\kappa \mathrm{B}$ was analyzed by an immunocytochemistry assay in the BV-2 cells. As shown in Fig. 5, in the non-activated cells, the majority of phosphorylated NF- $\mathrm{kB}$ was localized in the cytoplasm. Upon LPS stimulation, the fluorescence intensity of phosphorylated NF- $\mathrm{KB}$ was enhanced and NF- $\mathrm{KB}$ was mostly translocated to the nucleus. Conversely, ISO I treatment prevented the nuclear translocation of phosphorylated $\mathrm{NF}-\kappa \mathrm{B}$. All these results suggested that ISO I blocked the activation of NF- $\mathrm{KB}$ induced by LPS.

ISO I reduces the enhanced phosphorylation of PI3K/Akt and $M A P K s$ induced by LPS. The PI3K/Akt signaling pathway has been shown to control the transactivation of NF- $\mathrm{KB}(21)$. Thus, to examine whether ISO I affects the PI3K/Akt pathway, the phosphorylation of PI3K and Akt in the BV-2 cells was detected. As shown in Fig. 6, LPS stimulation time-dependently increased the phosphorylation of both PI3K and Akt, which was significantly attenuated by ISO I treatment.

MAPKs, including p38, ERK and JNK, are involved in $\mathrm{NF}-\kappa \mathrm{B}$ activation and the synthesis of pro-inflammatory mediators in activated microglia (22). In our study, we also detected the expression of MAPKs in LPS-stimulated BV-2 cells. As shown in Fig. 7, LPS enhanced the phosphorylation of p38, JNK and ERK1/2. Both ISO I and Dex significantly alleviated the activation of MAPKs.

\section{Discussion}

Neuroinflammation with excessively activated microglia has been demonstrated to aggravate the pathophysiology of many neurodegenerative diseases, indicating the beneficial efficacy of microglia regulatory agents in the therapy of these disorders $(23,24)$. As disclosed in our previous study, total astragalosides alleviated neuroinflammation via the inhibition of iNOS and other inflammatory cytokines in mice with experimental autoimmune encephalomyelitis (25). Moreover, astragaloside IV, one of the saponin molecules within total astragalosides, has been shown to inhibit microglial activation via the glucocorticoid receptor-mediated signaling pathway (20). In this study, we demonstrated that another saponin molecule, ISO I, within total astragalosides, also inhibited the activation of microglia. In the BV-2 cells, it mitigated the LPS-induced production of pro-inflammatory mediators, such as NO, TNF- $\alpha$, iNOS and COX-2. Further experiments revealed that ISO I attenuated NF- $\mathrm{\kappa B}$ activation possibly by regulating the PI3K/Akt and MAPK signaling pathways.

The persistent and uncontrolled activation of microglia is one of the characteristics of neurodegenerative disorders $(26,27)$. Pro-inflammatory cytokines, such as NO, IL-1 $\beta$ and TNF- $\alpha$ released from overactivated microglia may lead to progressive neuronal damage and further activate the inflammatory cascade (28). In this study, ISO I treatment significantly reduced the release of NO and TNF- $\alpha$, decreased the protein levels of COX-2 and iNOS, and downregulated the mRNA expression levels of iNOS, TNF- $\alpha$ and IL-1 $\beta$, indicating that ISO I suppressed the inflammatory responses in microglia and may thus be beneficial in the treatment of neurodegenerative diseases.

In the inactive state, the inhibitory protein, I $\mathrm{B}$, binds to $\mathrm{NF}-\kappa \mathrm{B}$ dimmers that blocks the nuclear translocation of the latter. Upon inflammatory stimulation, IкB is phosphorylated, 

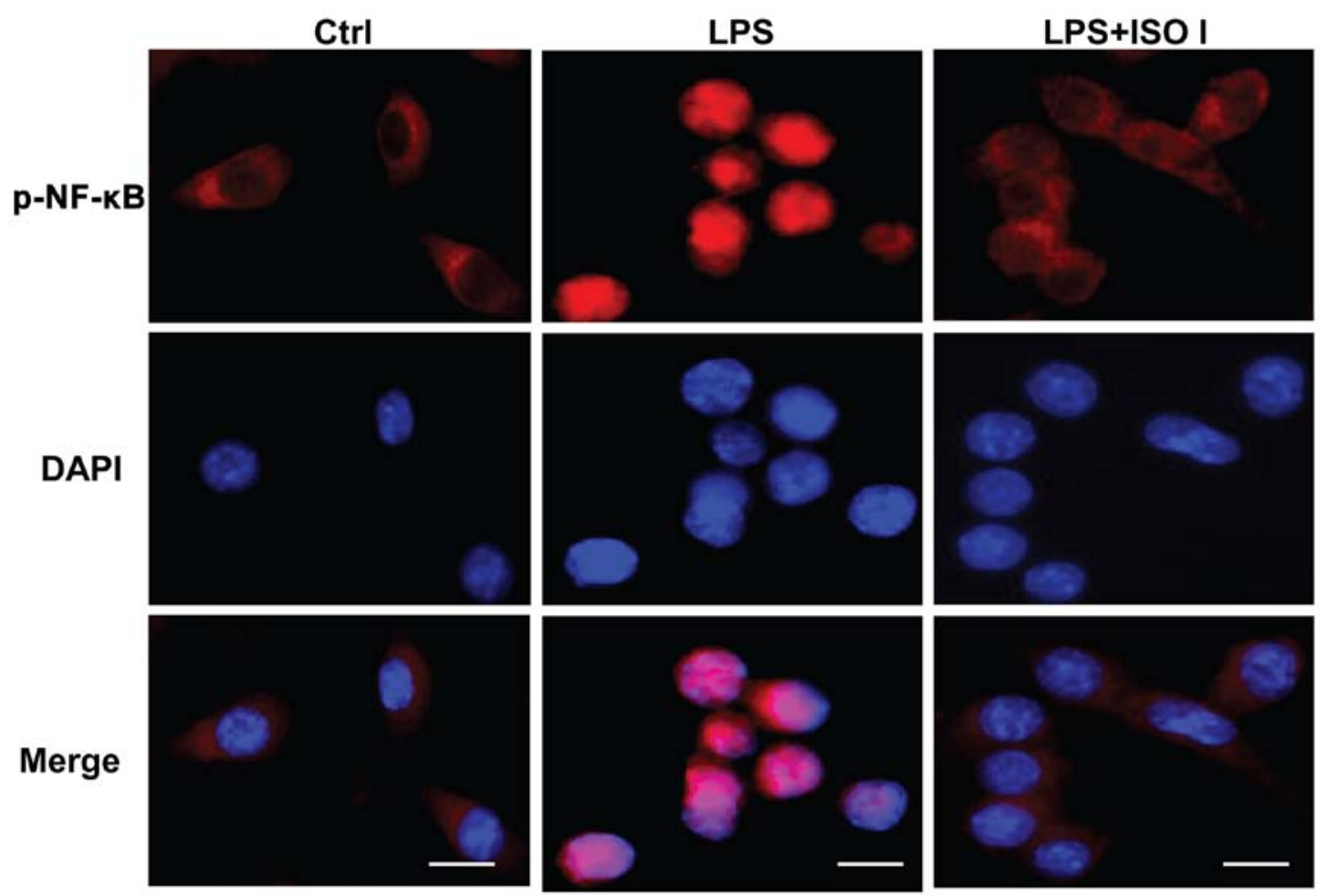

Figure 5. ISO I inhibits the lipopolysaccharide (LPS)-induced nuclear translocation of nuclear factor- $\mathrm{kB}(\mathrm{NF}-\mathrm{\kappa B})$ in BV-2 cells. Cells were treated with ISO I for $2 \mathrm{~h}$ prior to stimulation with LPS $(0.2 \mu \mathrm{g} / \mathrm{ml})$ for $20 \mathrm{~h}$. Scale bar, $20 \mu \mathrm{m}$. The data shown are one of the representative results from at least 3 independent experiments.

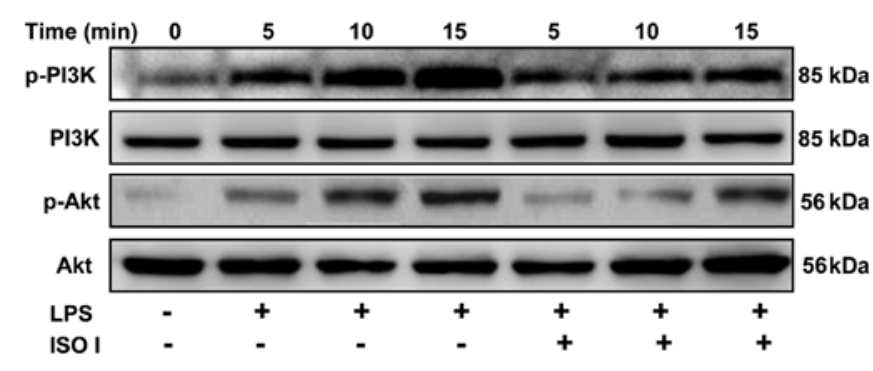

Figure 6. ISO I suppresses the phosphorylation of PI3K and Akt in lipopolysaccharide (LPS)-stimulated BV-2 cells. Cells were incubated with ISO I for $2 \mathrm{~h}$ prior to stimulation with LPS $(0.2 \mu \mathrm{g} / \mathrm{ml})$ for 5,10 and $15 \mathrm{~min}$. ISO I timedependently prevented the phosphorylation of PI3K and Akt. The data shown are one of the representative results from at least 3 independent experiments.

ubiquitinated and degraded sequentially. As a result, NF- $\mathrm{B}$ dimers will be translocated to the nucleus and regulate the transcription of downstream genes (29). In our study, ISO I significantly suppressed NF- $\kappa \mathrm{B}$ luciferase activity, reduced the phosphorylation of $\mathrm{NF}-\kappa \mathrm{B}$ and $\mathrm{I} \kappa \mathrm{B}$, and prevented the nuclear translocation of NF- $\kappa \mathrm{B}$ in LPS-stimulated BV-2 cells, accordingly, decreasing the downstream gene expression of inflammatory mediators. Therefore, our findings suggested that ISO I inhibited the inflammatory responses in microglia upon LPS stimulation via the NF- $\kappa \mathrm{B}$ pathway.

Signaling pathways, such as PI3K/Akt and MAPKs are well known to interact with the NF- $\kappa \mathrm{B}$ pathway, and therefore, are actively involved in the inflammatory cascade in microglia (30). In agreement with the reports $(31,32)$, in our study, LPS induced the prominent activation of PI3K/Akt and MAPKs. The effect of LPS was abrogated by ISO I, suggesting

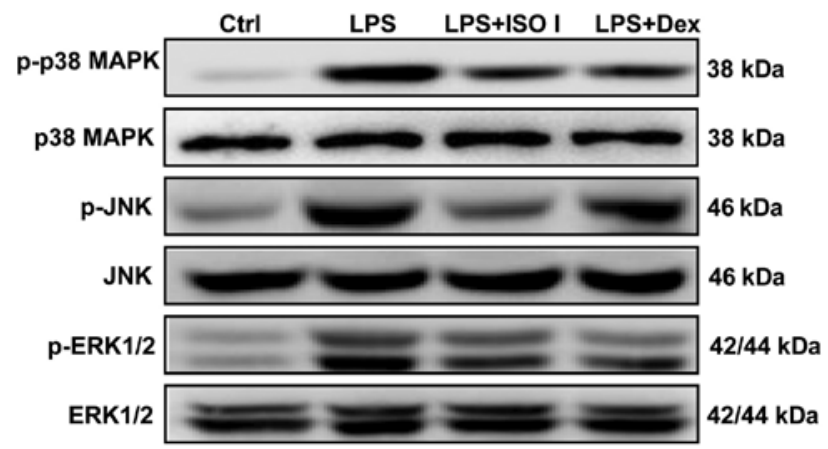

Figure 7. ISO I prevents the phosphoryaltion of mitogen-activated protein kinases (MAPKs) in lipopolysaccharide (LPS)-stimulated BV-2 cells. BV-2 cells were treated with ISO I for $2 \mathrm{~h}$ prior to LPS $(0.2 \mu \mathrm{g} / \mathrm{ml})$ incubation for $20 \mathrm{~h}$. Phosphorylation of p38, JNK and ERK was examined by western blot analysis.

that the anti-inflammatory effects of ISO I may be possibly mediated through these signaling pathways.

In conclusion, the present study demonstrated that ISO I attenuated LPS-induced inflammatory responses in BV-2 microglia, and these effects were probably mediated via the inhibition of $\mathrm{NF}-\kappa \mathrm{B}$ activation through the PI3K/Akt and MAPK signaling pathways.

\section{Acknowledgements}

This study was supported by the National Natural Science Foundation of China (81673626, 81603354), Shanghai Eastern Scholar Program (2013-59) and Shanghai E-research Institute of Bioactive Constituent in TCM plan. 


\section{References}

1. Glass CK, Saijo K, Winner B, Marchetto MC and Gage FH: Mechanisms underlying inflammation in neurodegeneration. Cell 140: 918-934, 2010.

2. Spencer JP, Vafeiadou K, Williams RJ and Vauzour D: Neuroinflammation: modulation by flavonoids and mechanisms of action. Mol Aspects Med 33: 83-97, 2012.

3. Akiyama H, Barger S, Barnum S, Bradt B, Bauer J, Cole GM, Cooper NR, Eikelenboom P, Emmerling M, Fiebich BL, et al: Inflammation and Alzheimer's disease. Neurobiol Aging 21: 383-421, 2000.

4. Bi W,Zhu L, Wang C, Liang Y, Liu J, Shi Q and Tao E: Rifampicin inhibits microglial inflammation and improves neuron survival against inflammation. Brain Res 1395: 12-20, 2011.

5. Wright JG and Christman JW: The role of nuclear factor kappaB in the pathogenesis of pulmonary diseases: implications for therapy. Am J Respir Med 2: 211-219, 2003.

6. Wullaert A: Role of NF-kappaB activation in intestinal immune homeostasis. Int J Med Microbiol 300: 49-56, 2010.

7. Calzado MA, Bacher S and Schmitz ML: NF-kappaB inhibitors for the treatment of inflammatory diseases and cancer. Curr Med Chem 14: 367-376, 2007.

8. Li N, Liu BW, Ren WZ, Liu JX, Li SN, Fu SP, Zeng YL, Xu SY, Yan X, Gao YJ, et al: GLP-2 attenuates LPS-induced inflammation in BV-2 cells by inhibiting ERK1/2, JNK1/2 and NF- $\mathrm{B}$ signaling pathways. Int J Mol Sci 17: 190, 2016.

9. Song F, Zeng K, Liao L, Yu Q, Tu P and Wang X: Schizandrin A inhibits microglia-mediated neuroninflammation through inhibiting TRAF6-NF- $\kappa \mathrm{B}$ and Jak2-Stat3 signaling pathways. PLoS One 11: e0149991, 2016.

10. Nan ZD, Zhao MB, Zeng KW, Tian SH, Wang WN, Jiang Y and Tu PF: Anti-inflammatory iridoids from the stems of Cistanche deserticola cultured in Tarim Desert. Chin J Nat Med 14: 61-65, 2016.

11. Zhang C, Liu BY, Zeng KW, Guo XY, Jiang Y and Tu PF: New sesquiterpene and thiophene derivatives from Artemisia rupestris J Asian Nat Prod Res 17: 1129-1136, 2015.

12. Liu J, Huang D, Xu J, Tong J, Wang Z, Huang L, Yang Y, Bai X, Wang $\mathrm{P}$, Suo $\mathrm{H}$, et al: Tiagabine protects dopaminergic neurons against neurotoxins by inhibiting microglial activation. Sci Rep 5: 15720, 2015

13. Rios JL and Waterman PG: A review of the pharacology and toxicology of Astragalus. Phytother Res 11: 411-418, 1997.

14. Liu G, Song J, Guo Y, Wang T and Zhou Z: Astragalus injection protects cerebral ischemic injury by inhibiting neuronal apoptosis and the expression of JNK3 after cerebral ischemia reperfusion in rats. Behav Brain Funct 9: 36, 2013.

15. Cheng CY, Yao CH, Liu BS, Liu CJ, Chen GW and Chen YS The role of astragaloside in regeneration of the peripheral nerve system. J Biomed Mater Res A 76: 463-469, 2006.

16. Lei H, Wang B, Li WP, Yang Y, Zhou AW and Chen MZ: Anti-aging effect of astragalosides and its mechanism of action. Acta Pharmacol Sin 24: 230-234, 2003.

17. Li WZ, Wu WY, Huang DK, Yin YY, Kan HW, Wang X, Yao YY and Li WP: Protective effects of astragalosides on dexamethasone and $A \beta_{25-35}$ induced learning and memory impairments due to decrease amyloid precursor protein expression in 12-month male rats. Food Chem Toxicol 50: 1883-1890, 2012.
18. Hirotani M, Zhou Y, Rui H and Furuya T: Cycloartane triterpene glycosides from the hairy root cultures of Astragalus membranaceus. Phytochemistry 37: 1403-1407, 1994.

19. Xu A, Wang H, Hoo RL, Sweeney G, Vanhoutte PM, Wang Y, Wu D, Chu W, Qin G and Lam KS: Selective elevation of adiponectin production by the natural compounds derived from a medicinal herb alleviates insulin resistance and glucose intolerance in obese mice. Endocrinology 150: 625-633, 2009.

20. Liu HS, Shi HL, Huang F, Peterson KE, Wu H, Lan YY, Zhang BB, He YX, Woods T, Du M, et al: Astragaloside IV inhibits microglia activation via glucocorticoid receptor mediated signaling pathway. Sci Rep 6: 19137, 2016.

21. Arbibe L, Mira JP, Teusch N, Kline L, Guha M, Mackman N, Godowski PJ, Ulevitch RJ and Knaus UG: Toll-like receptor 2-mediated NF-kappa B activation requires a Rac1-dependent pathway. Nat Immunol 1: 533-540, 2000.

22. Leung KW, Yung KK, Mak NK, Chan YS, Fan TP and Wong RN: Neuroprotective effects of ginsenoside-Rg1 in primary nigral neurons against rotenone toxicity. Neuropharmacology 52: 827-835, 2007.

23. Dang Y, Mu Y, Wang K, Xu K, Yang J, Zhu Y and Luo B: Papaverine inhibits lipopolysaccharide-induced microglial activation by suppressing NF- $\kappa$ B signaling pathway. Drug Des Devel Ther 10: 851-859, 2016.

24. Luo XL, Liu SY, Wang LJ, Zhang QY, Xu P, Pan LL and Hu JF: A tetramethoxychalcone from Chloranthus henryi suppresses lipopolysaccharide-induced inflammatory responses in BV2 microglia. Eur J Pharmacol 774: 135-143, 2016.

25. He YX, Du M, Shi HL, Huang F, Liu HS, Wu H, Zhang BB, Dou W, Wu XJ and Wang ZT: Astragalosides from Radix Astragali benefits experimental autoimmune encephalomyelitis in C57BL/6 mice at multiple levels. BMC Complement Altern Med 14: 313, 2014.

26. Das $\mathrm{S}$ and Basu A: Inflammation: a new candidate in modulating adult neurogenesis. J Neurosci Res 86: 1199-1208, 2008.

27. Perry VH, Nicoll JA and Holmes C: Microglia in neurodegenerative disease. Nat Rev Neurol 6: 193-201, 2010.

28. Lull ME and Block ML: Microglial activation and chronic neurodegeneration. Neurotherapeutics 7: 354-365, 2010.

29. Siddique I and Khan I: Mechanism of regulation of Na-H exchanger in inflammatory bowel disease: role of TLR-4 signaling mechanism. Dig Dis Sci 56: 1656-1662, 2011.

30. Hussain AR, Ahmed SO, Ahmed M, Khan OS, Al Abdulmohsen S, Platanias LC, Al-Kuraya KS and Uddin S: Cross-talk between NFkB and the PI3-kinase/AKT pathway can be targeted in primary effusion lymphoma (PEL) cell lines for efficient apoptosis. PLoS One 7: e39945, 2012.

31. Jung JS, Choi MJ, Lee YY, Moon BI, Park JS and Kim HS: Suppression of lipopolysaccharide-induced neuroinflammation by morin via MAPK, PI3K/Akt, and PKA/HO-1 signaling pathway modulation. J Agric Food Chem 65:373-382, 2017.

32. Guo C, Yang L, Wan CX, Xia YZ, Zhang C, Chen MH, Wang ZD, Li ZR, Li XM, Geng YD and Kong LY: Anti-neuroinflammatory effect of sophoraflavanone G from Sophora alopecuroides in LPS-activated BV-2 microglia by MAPK, JAK/STAT and Nrf2/HO-1 signaling pathways. Phytomedicine 23: 1629-1637, 2016. 